\title{
Minimizing Noise in Sinusiodal Function Signal using Wavelet Transform
}

\author{
Irpan Hidayat, Made Suangga, Roesdiman Soegiarso, Putri Arumsari, Yuliastuti
}

\begin{abstract}
Resistances that occur in retrieving and processing signal is caused by the interference (noise) on the data signal measurement results. The resistance will raise uncertainties in determining the value of the frequency. This is due to the signal which is mixed with the noise in the original signal. In general, the process of signal analysis uses Fast Fourier Transformation (FFT). However, by using FFT in analyzing and reconstructing there are still doubts in determining the real frequency due to the still visible noise in the signal. In this study the signal function used is a sinusiodal function, $Y=2 \sin \pi f_{1} t+2 \sin \pi f_{2} t$, with a given noise value of $2 \mathrm{DB}$. The specified frequency value of $f_{1}$ and $f_{2}$ equal to $0.25 \mathrm{~Hz}$ and $5 \mathrm{~Hz}$, respectively. This research proposed wavelet transforms to analyze and in filtering original signal with noise. By using the transformation wavelet, signal with noise filtered with the high pass and low pass filter method and also using the Haar wavelet function in analyzing. Once the signal is decomposed using wavelet transformation, the wavelet coefficients value will be obtained. The wavelet coefficient values will then threshold within a range of 5-50\%. The purposed in determining the treshold value is to reduce the signal data identified as a noise signal data. If the value of wavelet coefficient below the treshold percentage value multiplied by the maximum wavelet coefficient, it is identified as a noise signal data, and the value of coefficient wavelet will be zero. The wavelet coefficient will then be reconstructed in order to obtain the data signal with the new sinusoidal function. In determining the value of the reconstructed frequency signal, the Fast Fourier Transform (FTT) method is used. The results of the study is signals with noise can be analyzed and filtered using wavelet transforms, by changing the signal into wavelet coefficients. Furthermore, the threshold of $5 \%$ is capable in reducing of noise in signal so that the graph of frequency and amplitude showed a clearer value of frequency.
\end{abstract}

Keywords : signal, noise, wavelet transformation

Revised Manuscript Received on December 30, 2019.

* Correspondence Author

Irpan Hidayat*, Civil Engineering Department, Bina Nusantara University, Jakarta, Indonesia. Email: irpan@binus.edu

Made Suangga, Civil Engineering Department, Bina Nusantara University, Jakarta, Indonesia. Email: suangga@binus.edu

Roesdiman Soegiarso, Civil Engineering Department, Tarumanagara University, Jakarta, Indonesia. Email: roesdimans@pps.untar.ac.id

Putri Arumsari, Civil Engineering Department, Bina Nusantara University, Jakarta, Indonesia. Email: parumsari@binus.edu

Yuliastuti, Civil Engineering Department, Bina Nusantara University, Jakarta, Indonesia. Email: juliastuti@binus.ac.id

(C) The Authors. Published by Blue Eyes Intelligence Engineering and Sciences Publication (BEIESP). This is an open access article under the CC BY-NC-ND license (http://creativecommons.org/licenses/by-nc-nd/4.0/)

\section{INTRODUCTION}

$\mathrm{T}$ o obtain a frequency value and vibrate testing mode on the field, a signal analysis process generally used is the Fast Fourier Transform (FFT). Resistances that occur in retrieving and processing signal are caused by the interference (noise) on the data signal measurement results. The challenges that occur during the retrieval and signal process is the noise on the signal data measurement results. Due to the challenges it creates uncertainties in determining the first vibration mode of the frequency value on the FTT diagram. This is also due to the noise in original signal. Noise is one of the challenge in detecting damages [4], [5]. Fourier transformation uses windows in the process of signal analysis. Fourier analysis technique applies window shift, which is generally shaped in fixed box and taper in determining the local spectrum of a certain data [1].

Another method in determining local spectrum Wavelet analysis. It also uses the window technique. The difference is that the window in the wavelet is adjusted based on the scale therefore the small scaled variables can be well localized, however the large scale is difficult to be localised. The difference between the transformation Fourier technique and the wavelet are illustrated on Figure 1 [1].

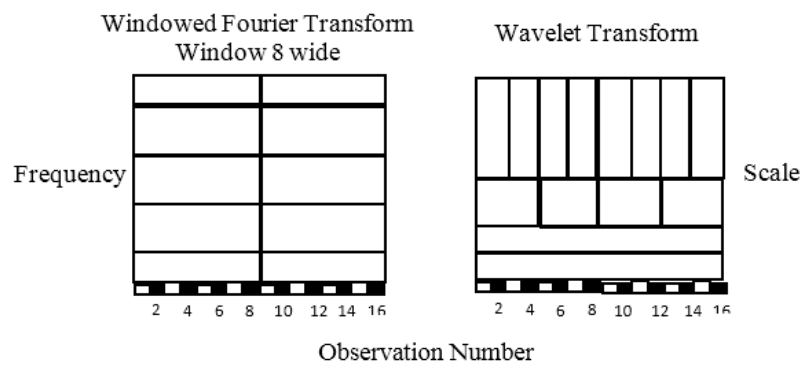

Fig 1. Schematic comparison of the fourier transformation and wavelet transformation [1]

Figure 1 shows a schematic diagram in the field for both frequency analysis techniques with large and small window sizes. Interpretation of Fourier analysis generally has problems in cases where a series of rows of the function $y(x)$ is a series of transient feature [1]. For cases like this, wavelet analysis will be more useful in solving the transient feature. Another challenge is on the frequency resolution, the ability to differentiate spectral response of two or more signals. This limitation is caused by data windowing, which causes leakage in the spectral domain. This limitation can have adverse affect when analyzing short data records. In practical test on the field, data measurements are measured in short duration [6]. 
The similarity of the two methods is that the data series is analyzed with no regard to the specific locations reviewed. Fourier analysis will decipher the data around the wave number $\mathrm{N} / 2$ with a length of $\mathrm{N}$ data series, whereas the wavelet analysis will decipher the data with a scale of $\log 2$ $\mathrm{N}$. A number of decisions have to be made in the analysis of data using each approach. When using the Fourier analysis, the necessity of lowering the data,

The amount and form of data that must be applied, and the type of smoothing applied to estimate local spectral need to be decided. While when using the wavelet analysis, to some degree the polynomial trend can be automatically eliminated, where the user needs to decide which wavelet type to use and the boundary conditions are at the end of the data series [1].

\section{DISCRETE WAVELET TRANSFORM}

Discrete Wavelet Transform (DWT) is uses a series of observational data in the amount of $\mathrm{N}$ to determine the wavelet coefficients. Wavelet coefficients will show the amount of the amplitude at location points using a scale that is determined, to then do several different pass band filtering processes. Decomposition is carried out sequentially, starting with the smallest scale and continued with the doubling the scale thereafter until it reaches a certain level. The initial assumption of the sample size is the power of two $2, \mathrm{~N}=2 \mathrm{~L}$. The value of $\mathrm{N}$ is a power of two, which at the final stage of decomposition it produces a single wavelet coefficients for the largest scale that may exist, but in practice the decomposition is often only up to the intermediate level. This is due to the significant complexity of influence at the end of the data series [1].

Filtration is one of the signal processing functions which is generally used. Wavelets can be done by filtering iteration by rescaling. The resolution of the signal is the size of a number of detailed information of the signal which is determined by the filtration operation and the scale of the up-sampling and down-ampling operation [2]. DWT is calculated by using the lowpass and highpass filtration sequentially from discrete time domain signal as shown in Figure 2. This is called a Mallat algorithm or a Mallat-tree decomposition. This is significant in connecting the continuous multi resolution time with the discrete filtered time. On Figure 2, the signal is represented by the sequence $x$ [n], where $n$ is an integer. The low pass filter is denoted by $\mathrm{G}$ while the high pass filter is denoted by $\mathrm{H}$. At each level, the high pass filter produces detailed information, $d[n]$, while the low pass filter is associated with the scaling function to produces a rough estimate, a [n] [6].

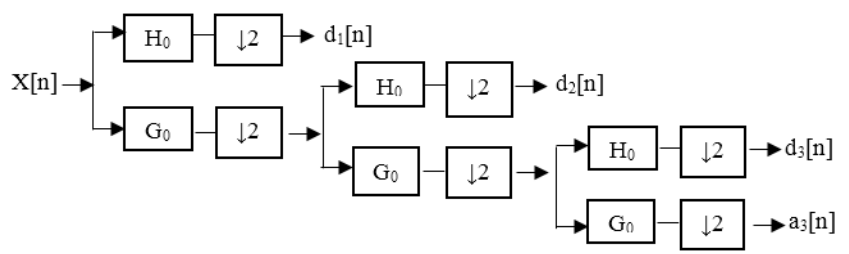

Fig 2. Schematic wavelet decomposition at level 3 [6]

The discrete wavelet transformation decipher a certain vector observation $y=\{y(x i), i=1$ to $N\}$, where $x i=x 0+$ $\mathrm{i} \Delta \mathrm{x}$, xo is the offset, and $\Delta \mathrm{x}$ is the interval. Decomposition using wavelet orthonormal basis $\psi \mathrm{j}$ vector, $\mathrm{k}=\{\psi \mathrm{j}, \mathrm{k}(\mathrm{xi}), \mathrm{i}=$ 1 to $\mathrm{N}\}$ can be set into the $\mathrm{j}$ index scale. Each vector on $\mathrm{j}$ scale is distinguished by the location of $\mathrm{k}$ index. $\mathrm{J}$ index scale runs from 1 to $\mathrm{L}$, and the physical scale associated with the $\mathrm{j}$ scale is formulated by $s j=\Delta x 2 j-1$. This orthonormal vector can be used to decipher the sequence of the series as in the Fourier analysis, but unlike the sine and cosine functions in Fourier transformation, $\psi \mathrm{j}, \mathrm{k}$ vector is localized in space, which means that only a portion of each of the vectors is not zero (except for the ones associated with the largest scale). Location of the $\mathrm{k}$ index usually indicates the location the non-zero of the non-zero of each determined scale. Half of the location of the data series is required for each shift in scale which is determined, and $\mathrm{k}$ runs from 1 to 2 -jn. In addition, the length of the non zero vectors is approximately twice the length of each step scaled [1].

As can be seen, the basis of the vectors in the wavelet is formed by the process of translationand convolution of elements by passing the vector into the highpass $(\mathrm{H})$ and lowpass $(G)$ filter functions, so that the range of scales and locations are represented. The $H$ and $G$ filters can be represented as vectors of length $m$, where $m$ is generally even integers. Filtering is done by convolution operation defined below. The smallest scale of the base wavelet vector $(j=1)$ is based on a shifted version of the filtered wavelet. Therefore only the $\mathrm{m}$ elements from the vector $\psi \mathrm{j}$, $\mathrm{k}$ is not zero. Often, only filtered banks with low pass filter and a high pass filter is used. Diagram of the filtered bank is shown in Figure 3 [3].

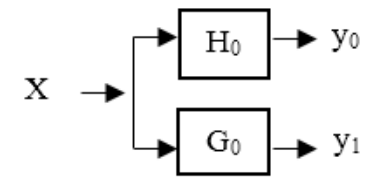

Fig 3. Simple filtered bank [3]

The simplest process for maternal wavelet screening is the Haar wavelet, which is based on the lag-one difference in the data set. Haar wavelet filtering with filter length $\mathrm{m}=2$. Filtering with the mother wavelet is a vector with elements [3].

\section{HAAR WAVELET}

The Haar Wavelets will give simpler results. The first thing to understand is that Haar's baby wavelets are orthogonal to one another. The function of the Haar wavelet is a one-cycle squared wave with 1 period [7]

$$
w(t)=\left\{\begin{array}{cc}
1 & 0 \leq t \leq 1 / 2 \\
-1 & 1 / 2<t<1 \\
0 & \text { others }
\end{array}\right\}
$$

so that

$$
w_{j k}(t)=\sqrt{2^{j}} w\left(2^{j} t-k\right)
$$

The factor $\sqrt{ }\left(2^{\wedge} \mathrm{j}\right)$ is used to make the same signal energy equal to 1 . The function of wj, $k(t)$ is the squared wave cycle that is extended from $k / 2 j$ to $(k+1) / 2 j$. From this information, it can be easily seen that the Haar wavelet baby, wj,m and wj,n are on the same scale, however 2-j is on a different position. For $\mathrm{m} / 2 \mathrm{j}$ and $\mathrm{n} / 2 \mathrm{j}$, are orthogonal, because the graphics are not overlapping. Moreover, this is also applicable for the baby Haar wavelet at different scales, which is also orthogonal [7]. 


\section{RESEARCH METHOD}

The research method as shown in Figure 4.

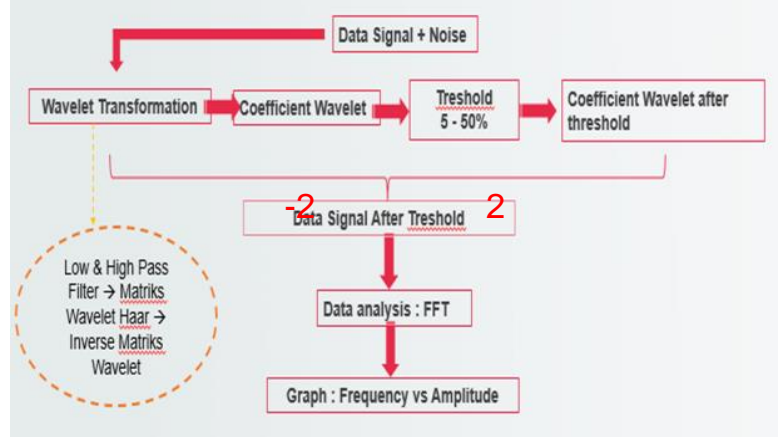

Fig 4. Research Method

The signal function used in this study is the sinusoidal function with the formula of $y=2 \sin \pi f 1 t$. Noise will be added to this signal function with at a certain number. The purpose of giving the noise into the original signal is to prove that the use of wavelet transformation can minimize noise compared to the Fourier transformation. By using the wavelet transformation, the signal will be filtered using the low and high-pass filters and using the Haar wavelet function for the analysis. So that the wavelet coefficient values for each level will be obtained in the form of approximation and detailed values. These wavelet coefficient values are then threshold within a range of $5-50 \%$. The percentage of the threshold number, for example a $5 \%$ threshold number will be multiplied by the largest value of the wavelet coefficient. This number will then become a benchmark in the process of filtering the wavelet coefficient value with the provision that the wavelet coefficient series value is lower than the wavelet percentage value multiplied by the largest value of the wavelet coefficient which is zeroed. So that a new data signal is formed which is the result of filtering using wavelet transformation. To get the frequency values using fast Fourier transform analysis. Hence the final result of this research is obtaining the frequency values from signal data that has been mixed with noise.

\section{RESULS AND DISCUSSION}

\section{A. Signal Data Observations}

The signal data used in this analysis are signals with sinusoidal functions $Y=2 \sin \pi f_{1} t+2 \sin \pi f_{2} t$. In this case the frequency value will be determined at $0.25 \mathrm{~Hz}$ and $5 \mathrm{~Hz}$. The noise used in the analysis is at number 2 and to generate a series of noise signal using the excel formula as follow NORMINV (RAND (), AVERAGE (F12: F101), 2). This means that most of the data in the distribution of about $68 \%$ will fall within, more or less one standard deviation from the mean value $(-2$ or +2$)$ shown in Figure 5 .

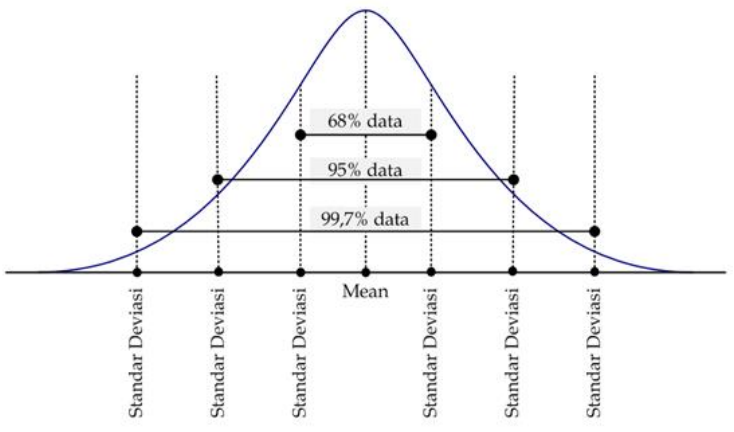

Fig 5. Schematic standard deviation [8]

Hence the data series of sinusoidal function with a frequency of $0.25 \mathrm{~Hz}$ and $0.5 \mathrm{~Hz}$ with a noise 2 as shown in the Figure 6.

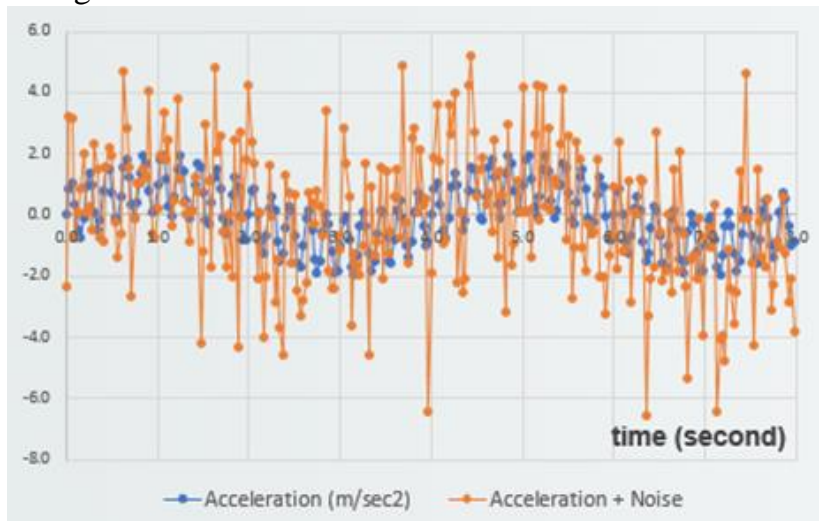

Fig 6. Original signals and noise for frequency of $0.25 \mathrm{~Hz}$ and $0.5 \mathrm{~Hz}$

The number of samples in Figure 6 is $\mathrm{N}=256$ samples in the duration of 8 seconds. Hence the sample frequency is analyzed using the wavelet transformation of $256 / 8=32 \mathrm{~Hz}$. This means that in one second 32 vibrations occur in a measurement.

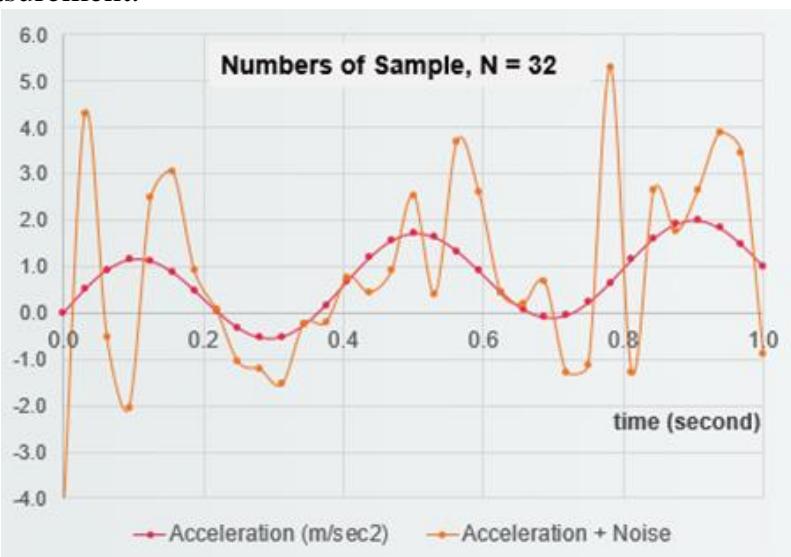

Fig 7. Frequency Sample $\mathbf{N}=32$

\section{B. Signal Decomposition}

Signal decomposition using the Haar wavelet for the time duration of 1 second. For the $N=32$ of the frequency samples, it requires $5^{\text {th }}$ decomposition level with the calculation as follow:

$\mathrm{J}=\log _{2}(\mathrm{~N})$

(3)

$\mathrm{J}=\log _{2}(32)$

$\mathrm{J}=5$ 
Hence the scale (j) to perform such decomposition level is as follow:

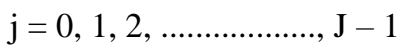

(4)

$\mathrm{j}=0,1,2,3,4$

Figure 8 is a process of decomposition of sinusoidal signal functions, with 32 number of frequency samples, $\mathrm{N}=32$, were analyzed by Haar wavelet function and scaling function. With the scale of $\mathrm{j}=5$ for decomposition using the Haar wavelet function, it will produce a 32x32 Haar matrix decomposition analysis shown in Table-II. Using wavelet transformation, by decomposing the signal, it will change the signals into wavelet coefficients.

The formula in determining the wavelet coefficient is as follows: Wavelet Coefficient $=$ Inverse Matrix $\mathrm{H}_{32 \times 32^{-1}} \cdot \mathrm{x}(\mathrm{t})$, where $x(t)$ is the signal to be analyzed. The results of the wavelet coefficient value will be seen in Table I.
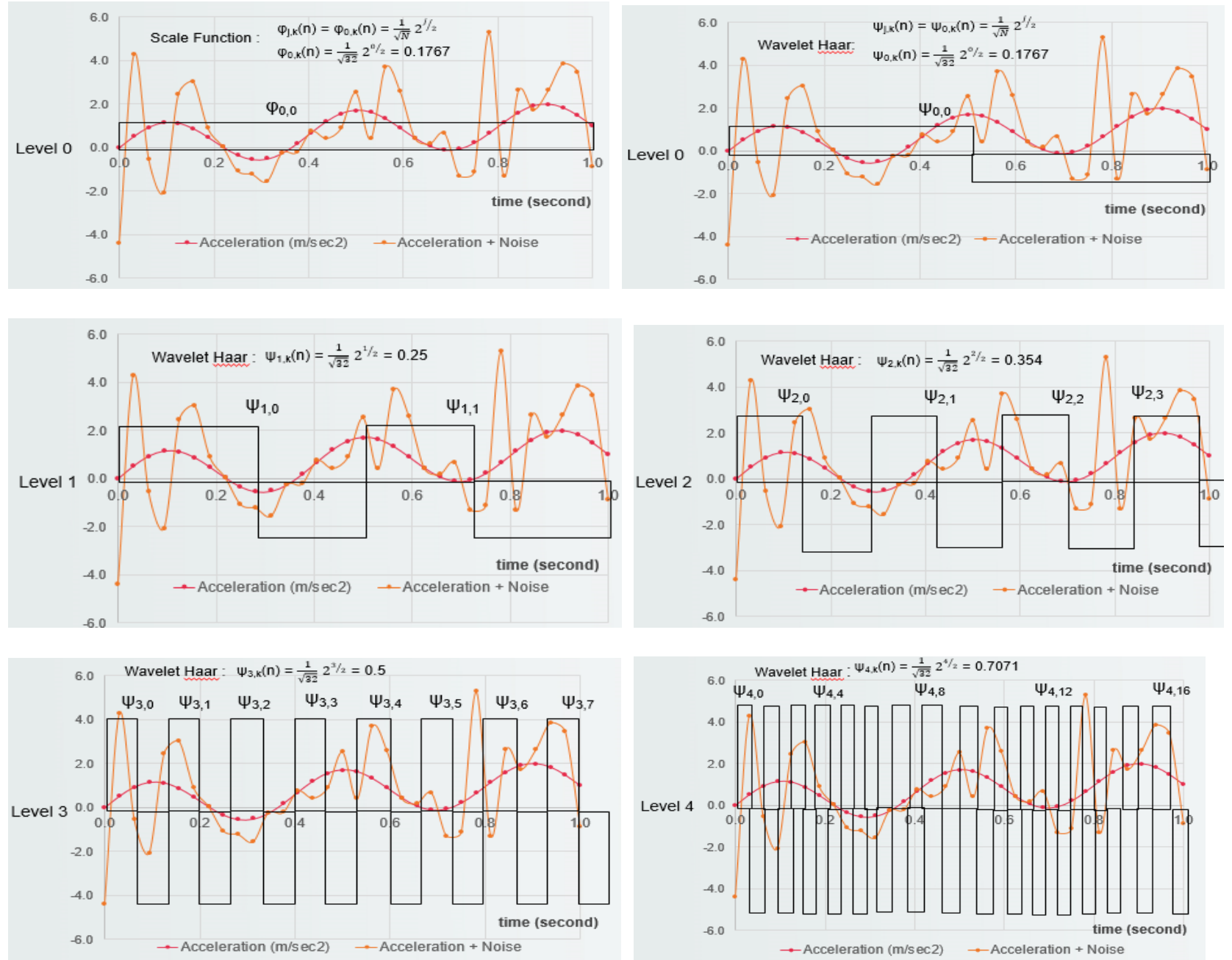

Fig 8. Decomposition of signals with wavelet haar to scale $\mathbf{j}=\mathbf{5}$ Table- I: Value function matrix 32x32 haar

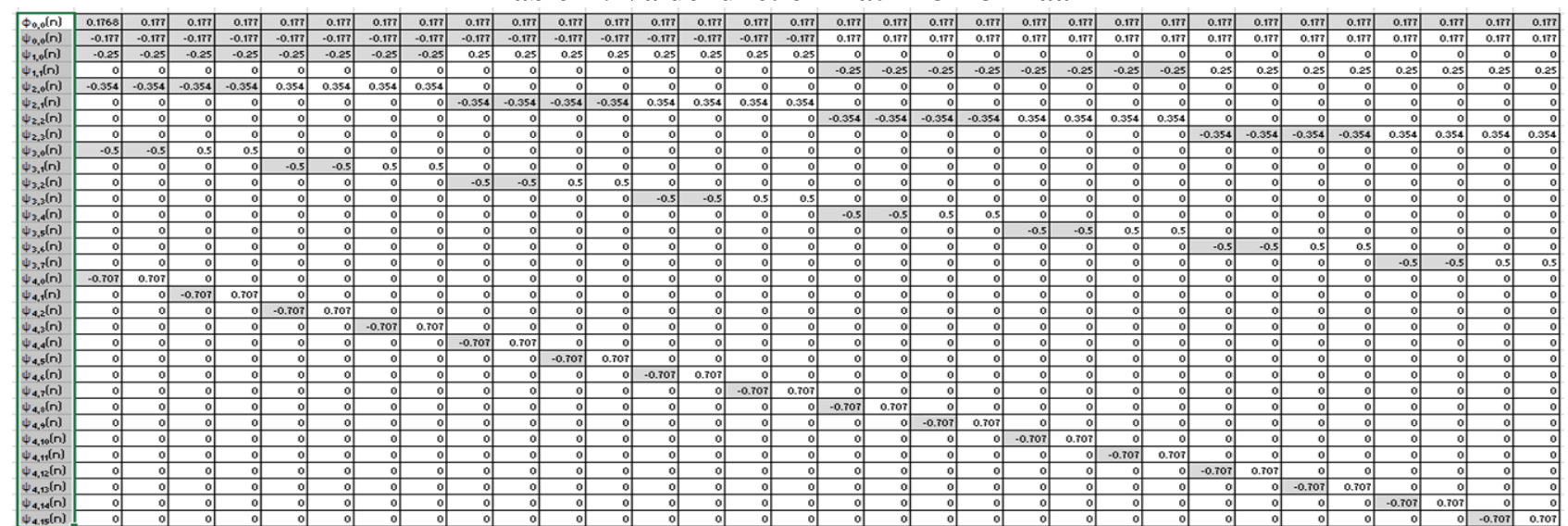


Table- II: Calculation of wavelet coefficients, threshold and FFT analysis

\begin{tabular}{|c|c|c|c|c|c|c|c|c|c|}
\hline No. & $\begin{array}{c}\text { Time } \\
\text { step (t) }\end{array}$ & $\begin{array}{c}\text { Original } \\
\text { Acceleration } \\
(\mathrm{m} / \mathrm{sec} 2)\end{array}$ & $\begin{array}{c}\text { Wavelet } \\
\text { Coefficient }\end{array}$ & $\begin{array}{l}\text { Frequency } \\
(\mathrm{Hz})\end{array}$ & $\begin{array}{c}5 \% \\
\text { Threshold }\end{array}$ & $\begin{array}{c}\text { Wavelet } \\
\text { Coefficient } \\
(5 \% \\
\text { Threshold })\end{array}$ & $\begin{array}{c}\text { Data } \\
\text { signals } \\
\text { after (5\% } \\
\text { Threshold) }\end{array}$ & FFT & $\begin{array}{c}\text { Amplitude } \\
\text { (Coefficient } \\
\text { Modulus) }\end{array}$ \\
\hline 0 & 0.00000 & -0.5712 & -0.5797 & 0.0000 & 3.65086E-09 & -0.5797 & -0.5712 & -0.677937314141154 & 0678 \\
\hline 1 & 0.03125 & 1.4136 & -1.5625 & 0.1250 & 3.65086E-09 & -1.5625 & 1.4136 & $0.223333300207095+2.32096782891599 i$ & 2,332 \\
\hline 2 & 0.06250 & 0.3912 & -1.3964 & 0.2500 & 3.65086E-09 & -1.3964 & 0.3912 & $2.55853699507029-124.469901372894 i$ & 124496 \\
\hline 3 & 0.09375 & -0.5456 & 1.1673 & 0.3750 & 3.65086E-09 & 1.1673 & -0.5456 & $5.36639552609806+2.95304026444993 i$ & 6,125 \\
\hline 4 & 0.12500 & 0.4078 & -5.0801 & 0.5000 & $3.65086 \mathrm{E}-09$ & -5.0801 & 0.4078 & $7.46811092896758+0.617381444805047 i$ & 7494 \\
\hline 5 & 0.15625 & 0.4103 & -0.3645 & 0.6250 & 3.65086E-09 & -0.3645 & 0.4103 & $7.92274072835018-2.75734150908195 i$ & 8389 \\
\hline 6 & 0.18750 & -0.7973 & 1.4702 & 0.7500 & 3.65086E-09 & 1.4702 & -0.7973 & 6.38421388959928-6.03395016722335i & 8784 \\
\hline 7 & 0.21875 & -1.6854 & 2.7564 & 0.8750 & 3.65086E-09 & 2.7564 & -1.6854 & $3.2265215853583-8.08283272714655 \mathrm{i}$ & 8703 \\
\hline 8 & 0.25000 & 0.9565 & -2.9615 & 1.0000 & 3.65086E-09 & -2.9615 & 0.9565 & $-0.600467203691782-8.19200149440634 \mathrm{i}$ & 8214 \\
\hline 9 & 0.28125 & 4.8355 & 1.3872 & 1.1250 & 3.65086E-09 & 1.3872 & 4.8355 & $-3.91806333222204-6.31179783588616 \mathrm{i}$ & 7,429 \\
\hline 10 & 0.31250 & 0.7779 & -0.9503 & 1.2500 & $3.65086 \mathrm{E}-09$ & -0.9503 & 0.7779 & $-5.7322698623917-3.05591297556997 \mathrm{i}$ & 6496 \\
\hline 11 & 0.34375 & 2.5034 & 0.9320 & 1.3750 & 3.65086E-09 & 0.9320 & 2.5034 & $-5.56500770773816+0.525879766282815 i$ & 5,590 \\
\hline 12 & 0.37500 & 4.3541 & -4.3512 & 1.5000 & 3.65086E-09 & -4.3512 & 4.3541 & $-3.59662031811599+3.31054361684182 \mathrm{i}$ & 4888 \\
\hline 13 & 0.40625 & 1.6085 & 1.6318 & 1.6250 & 3.65086E-09 & 1.6318 & 1.6085 & $-0.586342828981839+4.47189880557755 i$ & 4,510 \\
\hline 14 & 0.43750 & 1.5367 & 0.5921 & 1.7500 & 3.65086E-09 & 0.5921 & 1.5367 & $2.38925263035114+3.74072777822821 \mathrm{i}$ & 4,439 \\
\hline 15 & 0.46875 & 3.8362 & 1.6952 & 1.8750 & $3.65086 \mathrm{E}-09$ & 1.6952 & 3.8362 & $4.28958866646912+1.48191223044466 i$ & 4538 \\
\hline 16 & 0.50000 & -0.6949 & -1.8843 & 2.0000 & 3.65086E-09 & -1.8843 & -0.6949 & $4.44680715922019-1.42673747960737 i$ & 4,670 \\
\hline 17 & 0.53125 & 1.8128 & -1.3354 & 2.1250 & 3.65086E-09 & -1.3354 & 1.8128 & $2.78822039487754-3.87541057649249 \mathrm{i}$ & 4774 \\
\hline 18 & 0.56250 & 3.3344 & 3.6509 & 2.2500 & 3.65086E-09 & 3.6509 & 3.3344 & $-0.121795337994205-4.88357570200876 \mathrm{i}$ & 4885 \\
\hline 19 & 0.59375 & 0.9095 & 1.8377 & 2.3750 & 3.65086E-09 & 1.8377 & 0.9095 & $-3.24165266785309-3.93841256460144 \mathrm{i}$ & 5,101 \\
\hline 20 & 0.62500 & 3.0750 & -0.6022 & 2.5000 & 3.65086E-09 & -0.6022 & 3.0750 & $-5.38159934863143-1.20434561095019 \mathrm{i}$ & 5,515 \\
\hline 21 & 0.65625 & 1.3310 & -0.9994 & 2.6250 & 3.65086E-09 & -0.9994 & 1.3310 & $-5.61457523890208+2.47847232369762 \mathrm{i}$ & 6137 \\
\hline 22 & 0.68750 & 4.2306 & -0.5048 & 2.7500 & 3.65086E-09 & -0.5048 & 4.2306 & $-3.64002467884722+5.83458514127753 i$ & 6877 \\
\hline 23 & 0.71875 & 0.7800 & 2.1201 & 2.8750 & 3.65086E-09 & 2.1201 & 0.7800 & $3.63783423047614 \mathrm{E}-002+7.58222214847516 \mathrm{i}$ & 7582 \\
\hline 24 & 0.75000 & 0.3881 & -1.3041 & 3.0000 & 3.65086E-09 & -1.3041 & 0.3881 & $4.20282932466809+6.92037424369279 i$ & 8097 \\
\hline 25 & 0.78125 & -1.2821 & 0.9842 & 3.1250 & 3.65086E-09 & 0.9842 & -1.2821 & $7.32669763777758+3.89523063171437 i$ & 8298 \\
\hline 26 & 0.81250 & -0.2809 & 0.6285 & 3.2500 & 3.65086E-09 & 0.6285 & -0.2809 & $8.11627168355503-0.517642588926601 \mathrm{i}$ & 8,133 \\
\hline 27 & 0.84375 & 1.8561 & 2.1250 & 3.3750 & 3.65086E-09 & 2.1250 & 1.8561 & $6.05799386962112-4.69018523323863 i$ & 7,661 \\
\hline 28 & 0.87500 & 1.6181 & -1.4108 & 3.5000 & 3.65086E-09 & -1.4108 & 1.6181 & $1.70594059304019-6.91355018710594 i$ & 7,121 \\
\hline 29 & 0.90625 & 1.0581 & -3.5921 & 3.6250 & $3.65086 \mathrm{E}-09$ & -3.5921 & 1.0581 & $-3.42702940372275-6.06534286426299 i$ & 6967 \\
\hline 30 & 0.93750 & -1.5424 & 2.7456 & 3.7500 & 3.65086E-09 & 2.7456 & -1.5424 & $-7.37584268182142-2.1058490343789 i$ & 7,671 \\
\hline 31 & 0.96875 & -1.9953 & -0.0762 & 3.8750 & 3.65086E-09 & -0.0762 & -1.9953 & $-8.45518137328602+3.8203576708073 i$ & 9,278 \\
\hline
\end{tabular}

\section{Minimizing Noise Signal Analysis with Wavelet Coefficients and Treshold}

Minimizing the noise signal is done by changing the signal in the form of wavelet coefficients. Then the values generated as wavelet coefficient will then be reduced by withholding the wavelet coefficient values with the specified value of threshold. In this study, it will be threshold value is of $5 \%$ to $50 \%$.

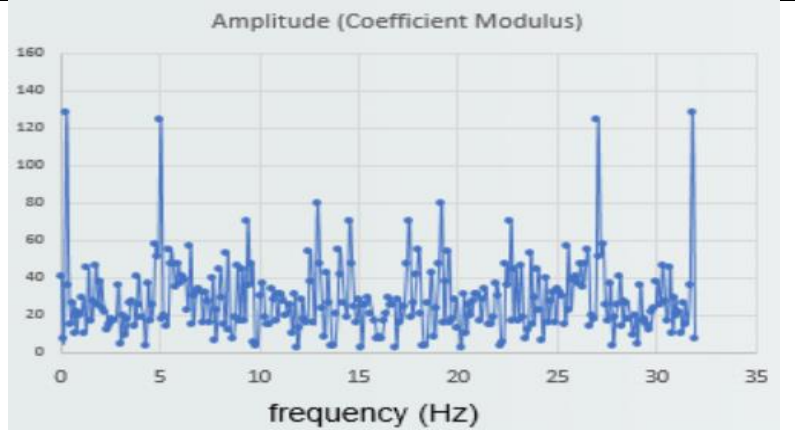

Fig 9. Comparative Analysis with and Without Filtering Wavelet Coefficients 


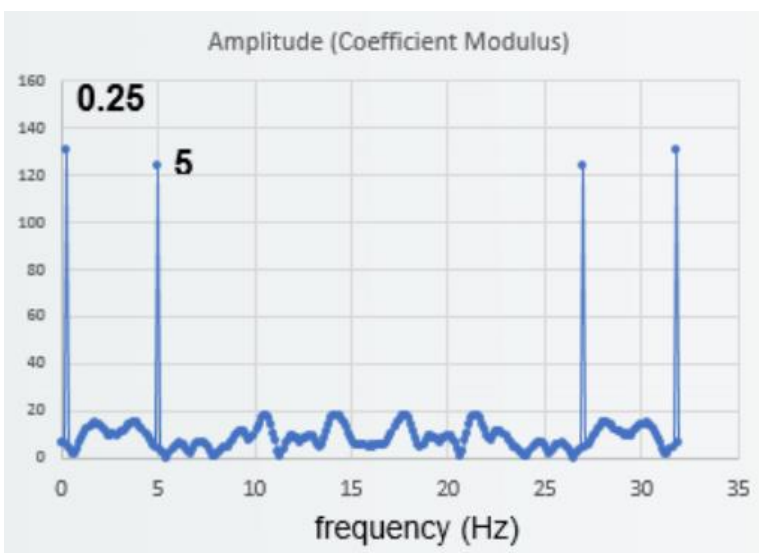

Fig 10. Comparative Analysis with and With Filtering Wavelet Coefficients (Treshold 5\%)

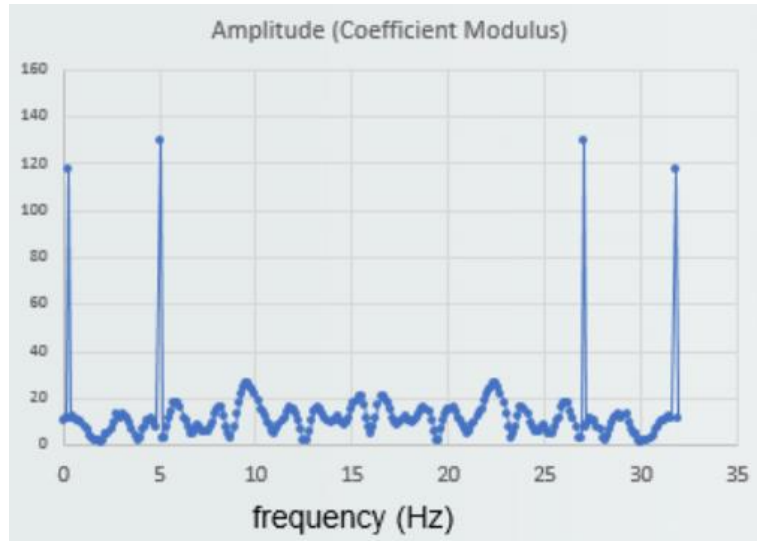

Fig 11. Comparative Analysis with and With Filtering Wavelet Coefficients (Treshold 10\%)

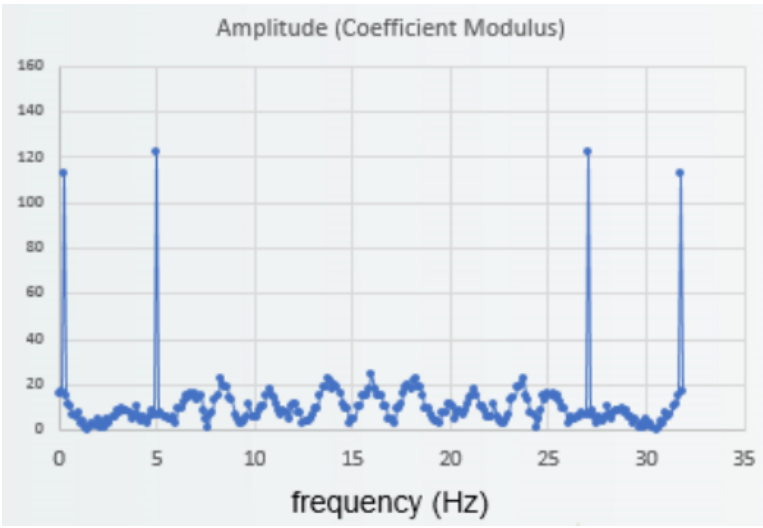

Fig 12. Comparative Analysis with and With Filtering Wavelet Coefficients (Treshold 20\%)

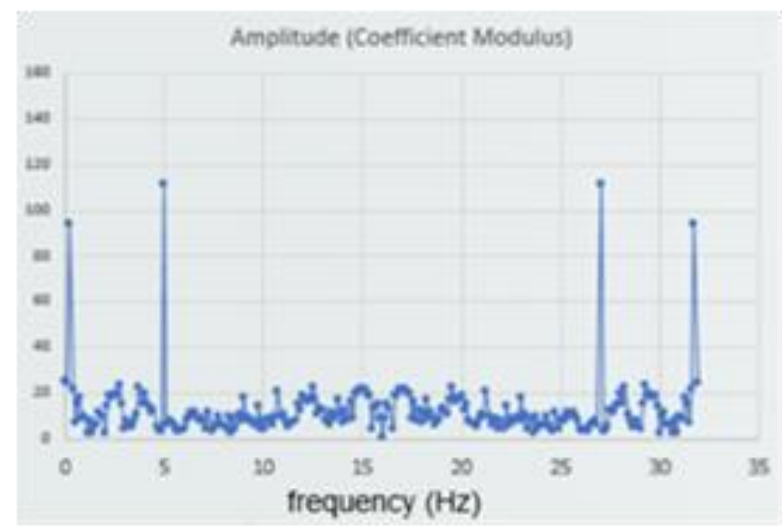

Fig 13. Comparative Analysis with and With Filtering Wavelet Coefficients (Treshold 40\%)

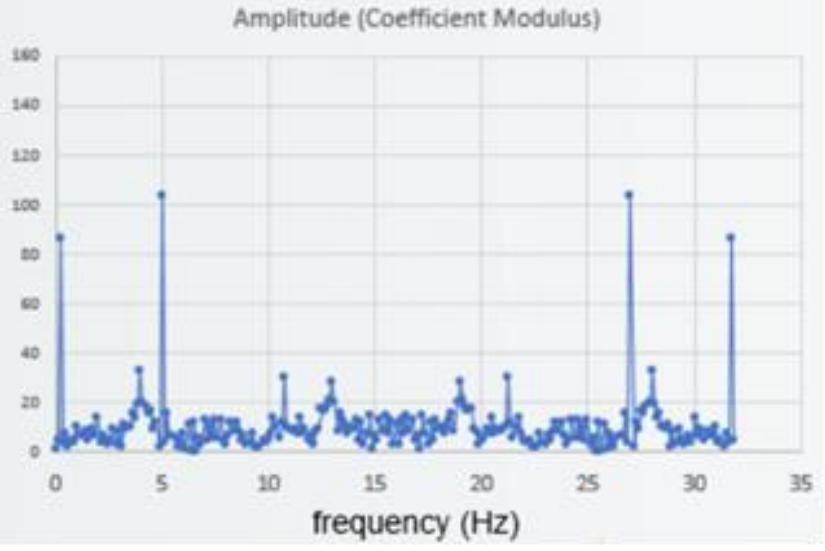

Fig 14. Comparative Analysis with and With Filtering Wavelet Coefficients (Treshold 50\%)

Based on Figure 9, using the Fourier transformation analysis and reconstruction, the first frequency is $0.25 \mathrm{~Hz}$ and the second frequency is $5 \mathrm{~Hz}$. This can be seen from the maximum amplitude value. However, in the frequency range of $0.25-5 \mathrm{~Hz}$ there are amplitude points which tend to be high therefore the frequency value set at the beginning is unknown. This result in doubts whether the amplitude points are frequency values from the signal or not [1].

When the signals were analyzed using the wavelet transformation using the low-pass and high-pass filtration and the Haar wavelet analysis as you can seen in Fugure 10, a $5 \%$ threshold is set. This results in a more convincing frequency graphic where the maximum amplitude points tapered up. This result can prove that the used of wavelet transforms by passing signals into the haar wavelet analysis and filtering with lowpass and high pass filter are able to reduce signal noise. Further research is done to analyze further on the affect of threshold frequency in reducing the wavelet coefficient value. With a $10 \%$ threshold, the frequency graphic with of $0.25-5 \mathrm{~Hz}$ does not show any tapered up amplitude points. However a $40 \%$ and 50\% threshold are able to show a high amplitude points in the frequency range of $0.25-5 \mathrm{~Hz}$. Based om Figure 13 and Figure 14, the treshold percentage value with a value of $40 \%$ and above is no longer effective, because it will cause some maximum amplitude points in range $0.25 \mathrm{~Hz}-5 \mathrm{~Hz}$ on the frequency and amplitude graphs, so that it will show back the signal data with noise.

\section{CONCLUSION}

Here are some temporary conclusions from this research:

1) Discrete wavelet transformation can convert signals with noise in the form of wavelet coefficients

2) Determination of the threshold value helps in the process of filtering the noise signal by passing the noise signal into the wavelet coefficient in a predetermined threshold value

3) The threshold process of $5 \%$ has been able to display clearer frequency values for a total number of 256 test samples. 


\section{ACKNOWLEDGMENT}

This work is supported by Directorate General of Strengthening for Research and Development, Ministry of Research, Technology, and Higher Education, Republic of Indonesia as a part of Penelitian Dasar Unggulan Perguruan Tinggi Research Grant to Binus University entitiled "Perhitungan Modal Parameter Struktur Kabel dengan Menggunakan Transformasi Wavelet" with contract number : 225/SP2H/LT/DRPM/2019; 12/AKM/PNT/2019; 039/VR.RTT/IV/2019 and contract date: 27 March 2019.

\section{REFERENCES}

1. R.W. Lindsay, D. B. Percival, D. A. Rothrock. The Discrete Wavelet Transform and the Scale Analysis of the Surface Properties of Sea Ice. 1996. IEEE Transactions on Geoscience and Remote, Vol. 34, No.3.

2. C. Taswell. The What How , and Why of Wavelet Shrinkage Denoising. 2000. Computing in Science and Engineering. Vol 2, No. 3, p.12-19.

3. F. Bömers. Wavelets in real time digital audio processing: Analysis and sample implementations. 2000. Unpublished.

4. I. Simonovski, M. Bolte. Damping Identification using a Continuous Wavelet Transform: Application to real data. 2003. J. Sound Vib. 262(2), 291-307.

5. V. Pakrashi, B. Basu. A. Connor. Structural damage detection and calibration using wavelet-kurtosis technique. 2007. Eng. Struct., 29(9), 2097-2108.

6. D. Gheorge, M. Chindris, A. Cziker, and R. B. Vasiliu. Fundamental Frequency Estimation Using Wavelet Denoising Techniques. 2010. 3rd International Conference on Modern Power System MPS.

7. D. Sundararajan. Fundamentals of the Discrete Haar Wavelet Transform. 2011.

8. C. Kyd,. How to Create Monte Carlo Models and Forecasts Using Excel Data Tables. 2014

\section{AUTHORS PROFILE}

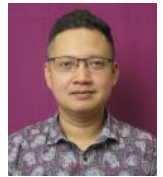

Irpan Hidayat is a lecturer at Civil Engineering Department, Bina Nusantara University in Jakarta, Indonesia. He completed his undergraduate study at the Bina Nusantara University (2005), Master Program in Structural Engineering at University of Indonesia (2011), and continued his doctor's program at Tarumanagara University with a focus on structural engineering.

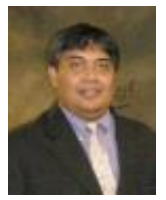

Made Suangga is a lecturer at Civil Engineering Department, Bina Nusantara University in Jakarta, Indonesia. He completed his undergraduate study at the Bandung Institute of Technology (1992), Master Program in Highway Engineering and System at the Bandung Institute of Technology (1995), and completed a doctoral program at Yokohama National University focusing on Wind and Bridge (2000).

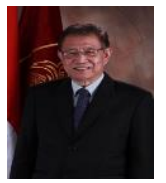

Roesdiman Soegiarso is a lecturer at Civil Engineering Department, Tarumanagara University in Jakarta, Indonesia. He completed his undergraduate study at the Parahyangan Catholic University (1972), Master Program in Highway Engineering and System at the Bandung Institute of Technology (1978), and completed a doctoral program at Ohio State University (1984).

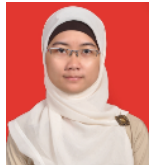

Putri Arumsari is a lecturer at Civil Engineering Department, Bina Nusantara University in Jakarta, Indonesia. She completed her undergraduate study at the Bina Nusantara University (2011), Master Program in Construction Management at University of Indonesia (2015).

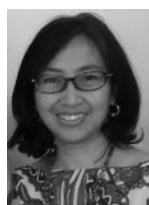

Yuliastuti is a lecturer at Civil Engineering Department, Bina Nusantara University in Jakarta, Indonesia. She completed her undergraduate study at the Parahyangan Catholic University (1992), Master Program in Water Resources at the University of Indonesia (2004), and continued her doctor's program at Tarumanagara University with a focus on Water Resources Management 